\title{
DA ESTRATÉGIA CLÁSSICA À ESTRATÉGIA COMO PRÁTICA: UMA ANÁLISE DAS CONCEPÇÕES DE ESTRATÉGIA E DE ESTRATEGISTAS
}

\section{RESUMO}

Este ensaio teórico objetivou analisar as concepções de estratégia e de estrategistas segundo diferentes vertentes: clássica, evolucionária, processual, sistêmica e estratégia como prática. Identificou-se que a concepção de estratégia varia entre as abordagens em relação a aspectos como influências teóricas, conceito de estratégia, finalidade da estratégia, protagonistas, processo estratégico, formação das estratégias, prazo para implementação e níveis de análise. A concepção de estrategista se modifica em relação à posição hierárquica, nível de racionalidade, função e atuação. Sobre temporalidade, formalização e racionalidade destaca-se que, em uma perspectiva evolucionária, há uma maior ênfase nas decisões limitadas de curto prazo, enquanto que, na clássica, a estratégia é constituída no longo prazo, com disponibilidade plena de racionalidade. O nível de análise pode direcionar a abrangência da pesquisa, haja vista que, na perspectiva da estratégia como prática, não poderá se limitar à narrativa do gerente de alto escalão e necessitará explorar a contribuição de todos os envolvidos no processo de fazer estratégia. Em contrapartida, uma visão evolucionária necessita explorar a realidade macroeconômica como diagnóstico para a formulação estratégica. Conclui-se que as concepções de estratégia e estrategista de acordo com cada vertente têm implicações diferentes para atuação de pesquisadores, docentes e gestores.

Palavras-chave: Estratégia; Estrategista; Vertentes Teóricas.

\section{FROM CLASSIC STRATEGY TO THE STRATEGY AS PRACTICE: AN ANALYSIS OF THE CONCEPTS OF STRATEGY AND STRATEGISTS}

\begin{abstract}
This theoretical essay aimed to analyze the concepts of strategy and strategists according to different approaches: classical, evolutionary, procedural, systemic and strategy as practice. It has been identified that the concept of strategy varies between approaches in relation to aspects such as theoretical influences, strategy concept, purpose of strategy, protagonists, strategic process, formation of strategies, deadline for implementation and levels of analysis. The concept of strategist changes in relation to the hierarchical position, level of rationality, role and performance. Regarding the temporality, formalization and rationality it is important to note that in an evolutionary perspective, there is a major emphasis on the short-term limited decisions, whereas in the classic one the strategy is constituted in the long-term, with total availability of rationality. The level of analysis can direct the scope of the research, considering that in the perspective of the strategy as practice, it will not be limited to the narrative of the high-level manager and it will be necessary to explore the contribution of everyone involved in the process of making strategy. On the other hand, a revolutionary view needs to explore the macroeconomic reality as a diagnostic for the strategic formulation. It is possible to conclude that the concepts of strategy and strategist according to each approach have different implications for the performance of researchers, teachers and managers.
\end{abstract}

Keywords: Strategy; Strategist; Theoretical approaches. 


\section{DE LA ESTRATEGIA CLÁSICA A LA ESTRATEGIA COMO PRÁCTICA: UN ANÁLISIS DE LAS CONCEPCIONES DE ESTRATEGIAS Y DE LOS ESTRATEGAS}

\section{RESUMEN}

Este ensayo teórico tuvo como objetivo analizar los conceptos de estrategia y estrategas bajo diferentes aspectos: clásica, evolutiva, de procedimiento, sistémica y la estrategia como práctica. Se identificó que la concepción de estrategia varía entre los enfoques de las cuestiones tales como las influencias teóricas, el concepto de estrategia, el propósito de la estrategia, los protagonistas, proceso estratégico, estrategias de formación, plazo de ejecución y niveles de análisis. La concepción de estratégia cambia en relación a la posición jerárquica, nivel de racionalidad, funcionalidad y rendimiento. Sobre la formalización, temporalidad y la racionalidad se destaca que, en una perspectiva evolutiva, hay un mayor énfasis en las decisiones limitadas a corto plazo, mientras que en el clásico, la estrategia consiste en el largo plazo, con plena disponibilidad de la racionalidad. El nivel de análisis puede dirigir el alcance de la investigación, dado que, en vista de la estrategia como práctica, no puede limitarse a la gerente narrativa y la necesidad de explorar la contribución de todos los involucrados en el proceso de hacer estrategia. Por el contrario, una visión evolutiva debe explicar la realidad macroeconómica como diagnóstico para la formulación de estrategias. Se concluye que los conceptos de estrategia y estratega de acuerdo con cada aspecto tienen diferentes implicaciones para la acción de los investigadores,

docentes

directivos.

Palabras clave: Estrategia; Estratega; Aspectos Teóricos.

\footnotetext{
${ }^{1}$ Doutorando em Administração na Universidade Federal do Paraná. Brasil. E-mail: eduardogvillar@gmail.com

${ }^{2}$ Doutora em Administração pela Pontifícia Universidade Católica do Paraná - PUC/PR. Professora dos cursos de Graduação em Administração, Mestrado Profissional em Administração e Mestrado Acadêmico em Ciências Contábeis da Universidade Estadual do Oeste do Paraná - UNIOESTE. Brasil. E-mail: silvanaanita.walter@gmail.com

${ }^{3}$ Doutoranda em Administração pelo Programa de Pós Graduação em Administração da Universidade Nove de Julho PPGA/UNINOVE. Professora do curso de Graduação em Ciências Contábeis da Universidade Estadual do Oeste do Paraná - UNIOESTE. Brasil. E-mail: lorenibraum@ hotmail.com
} 


\section{INTRODUÇÃO}

$\mathrm{Na}$ área de estratégia, existem diversas concepções teóricas e definições de estratégia organizacional. Dessa forma, apesar de a maior parte dos autores concordar que estratégias adequadas podem contribuir para a prosperidade das empresas, não existe uma definição comum do termo estratégia, muito menos o que é uma estratégia apropriada ou como chegar a ela (Barney \& Hesterly, 2007).

Essa variedade de concepções teóricas e definições de estratégia acarreta questionamentos por parte de gestores, pesquisadores, docentes e alunos. Isso porque cada perspectiva traz seus próprios pressupostos, níveis de análise, formas de atuação e concepção de estrategista. Nesse sentido, Mintzberg (2006a) considera que o reconhecimento das definições e dos significados de estratégia poderá auxiliar na evolução da área. A partir desse contexto, destaca-se a relevância de estudar as diferentes concepções de estratégia, a exemplo do que se faz neste ensaio teórico, cuja pergunta de pesquisa é assim definida: Como as concepções de estratégia e de estrategistas se alteram para as diferentes vertentes teóricas?

Para atingir o objetivo de analisar as concepções de estratégia e de estrategistas segundo diferentes vertentes teóricas, foram exploradas as abordagens clássica, evolucionária, processual e sistêmica, conforme realizado por Whittington (2002), acrescentando-se elementos e a perspectiva de estratégia como prática.

Apesar de existirem inúmeras tipologias de estratégia (Miles \& Snow, 1978; Chaffee, 1985; Mintzberg, Ahlstrand \& Lampel, 2000), a proposta de Whittington (2002) elucida uma diferenciação ontológica do processo estratégico, em detrimento das demais que irão trabalhar diferenciações eminentemente teóricas, metodológicas e/ou empíricas. Whittington (2002) combinar em uma matriz de classificação os constructos resultado e processo.

A inclusão da estratégia como prática, por sua vez, se deve ao destaque que esta vem ganhando com ampliação das publicações nacionais e internacionais; realização de eventos internacionais voltados a essa visão da estratégia; e abertura de temas de interesse voltados a ela em eventos nacionais (Walter \& Augusto, 2009). Quando Whittington (2002) publicou, em 2002, sua classificação das vertentes teóricas, a estratégia como prática era empregada em apenas quatro publicações no exterior (e nenhuma no Brasil) (WALTER \& AUGUSTO, 2009), o que pode explicar sua não-inclusão pelo autor.

Ressalta-se outros esforços de revisão conceitual na área de estratégia, tanto no âmbito internacional (Evered, 1983; Mintzberg, Ahlstrand \& Lampel, 2000; Oliver, 2001; Whittington, 2002) quanto nacional (Cabral, 1998). Contudo, não se encontrou um estudo que abordasse o conceito de estrategista para as abordagens, nem que incluísse a vertente de estratégia como prática.

Como justificativa da pesquisa indica-se que compreender o modo como o estoque disponível do conhecimento é organizado e disseminado torna-se um importante elemento desse próprio estoque de conhecimento (Berger \& Luckmann, 2012). A confusão em torno do conceito e das abordagens da estratégia tem sido uma constante na área, sendo que isso também gera dificuldades para alunos e docentes no processo de ensino-aprendizagem e também de gestores na aplicação destas correntes de conhecimento em sua atividade.

O presente artigo está estruturado em mais três seções, além desta introdução: na próxima, apresentase uma breve contextualização das abordagens teóricas consideradas neste estudo; na terceira, apresentam-se os resultados obtidos por meio das análises bibliográficas sobre o tema; e, na quarta, têm-se as considerações finais.

\section{BASE TEÓRICA}

O conhecimento, estudo e aplicação da estratégia tem origem militar. Nesse ensejo, o termo estratégia, oriundo do grego strategos, refere-se a um plano de guerra, isto é, um desenho de como os indivíduos atuarão, individualmente e em conjunto, em prol do objetivo pretendido (Clausewitz, 1976). Quinn e Voyer (2006) destacam que todos os pensadores e praticantes modernos usam os princípios da estratégia grega da Antiguidade nas diversas áreas, como governamental, diplomática, militar, empresarial e esportiva.

$\mathrm{Na}$ esfera empresarial e acadêmica, o tema emerge nos anos de 1900, na Universidade de Harvard, mais especificamente com a criação da cadeira Política de Negócios em 1912. Tal disciplina era ministrada na fase final do curso, que fundamentalmente trabalhava a administração de maneira funcional (Vizeu \& Gonçalves, 2010).

Contudo, somente nos anos de 1960 surgem os primeiros trabalhos sobre estratégia, frutos da cadeira Política de Negócios, de Harvard. Ressalta-se o trabalho do historiador Alfred Chandler, que, em 1962, publicou o livro "Strategy and structure", trazendo o termo para a área de negócios. Para Chandler (1962), a estratégia é uma visão dos objetivos organizacionais em longo prazo, e da viabilização de ações e recursos para atingi-los. Nesse sentido, a estratégia molda a estrutura da organização e modo de administrá-la.

O também professor da cadeira Política de Negócios, de Harvard, Kenneth Andrews, publica, em 1971, sua obra "The concept of corporate strategy", que é tida como a de maior relevância e influência para 
a disseminação do conceito de estratégia no âmbito organizacional. Além disso, tal autor é responsável pela criação do modelo de análise SWOT (Forças, Fraquezas, Oportunidades e Ameaças) que revolucionou a maneira de elaborar ações estratégicas (Vizeu \& Gonçalves, 2010). Segundo Andrews (1998), os objetivos ou propósitos de uma organização em longo prazo são determinados pela organização e estabelecerão a escala de negócio, o seu nível de envolvimento e a contribuição econômica e não econômica para os colaboradores, acionistas e comunidade.

Além de Chandler e Andrews, o executivo Alfred Sloan traz contribuições com a publicação, em 1963, de seu livro "My years with General Motors", no qual enfatiza o compromisso organizacional com a maximização do lucro. Dessa maneira, o objetivo estratégico de uma empresa está em viabilizar seu resultado econômico, de forma que se esse não for satisfatório em longo prazo, as ações devem ser revistas ou a organização deve abdicar das atividades em questão (Sloan, 1963).

Assim, para os três autores destacados (Chandler, Andrews e Sloan), o estrategista é o executivo principal da organização, o indivíduo capaz de internalizar todas as informações e conhecimentos necessários para visualização dos caminhos futuros da organização. De maneira solitária, o estrategista formula a estratégia e as ações subsequentes para o direcionamento da organização com vistas a maximizar seus resultados econômicos (Mintzberg et al., 2000).

Com o aumento da complexidade organizacional, emerge o trabalho do teórico, engenheiro e matemático Igor Ansoff em sua obra "Corporate Strategy" de 1965. Na obra, há um aumento da complexidade da análise SWOT, de Andrews. Também sugere uma programação metódica e a análise numérica de variáveis por meio da pesquisa operacional como forma de embasamento da formulação estratégica (Ansoff, 1965). Além disso, aponta a necessidade de decomposição das estratégias em subestratégias para o sucesso da implementação. Assim, a operacionalização de estratégias dá origem a todo um conjunto de hierarquias, em diferentes níveis (estratégico, tático e operacional). Portanto, estratégia é entendida como um dos vários conjuntos de regras de decisão utilizados para orientar o comportamento de uma organização (Ansoff, 1965).

Em adição, Ansoff (1965) defende a criação de grupos (ou departamentos) próprios de planejamento, que seriam responsáveis por todo esse processo de formulação da estratégia. Contudo, o executivo principal ainda é percebido como ponto fundamental da formulação, pois é ele quem aprova as estratégias criadas pelo grupo de planejadores. O executivo principal, portanto, necessita trabalhar de maneira racional e formal, com estratégias elaboradas à parte (planejadores) e promover sua difusão na organização para serem implementadas pelos gerentes operacionais (implementadores).

Como uma proposta voltada a questões do ambiente, o professor de Harvard, Michael Porter, advindo de uma formação economicista, apresenta uma visão estratégica baseada no posicionamento da organização perante o mercado em suas obras "Competitive strategy", de 1980, e "Competitive Advantage" de 1985 (Porter, 1991a; 2002b). Assim, a estratégia tem por objetivo estabelecer uma posição lucrativa e sustentável (vantagem competitiva) em contraposição às forças que promovem a concorrência nas empresas que possuem relação com o negócio da organização, ou seja, na indústria (Porter, 2002b).

Segundo Porter (2002b), dois fatores norteiam a escolha da estratégia competitiva. A primeira é a atratividade da indústria e tem por objetivo perceber a rentabilidade dessa indústria em longo prazo, assim como os fatores que determinam essa atratividade. A segunda são os determinantes da posição competitiva dentro de uma indústria. Dessa maneira, a meta final da estratégia competitiva consiste em conseguir modificar a atratividade da indústria em favor da empresa. O autor destaca que, em qualquer indústria, as regras da concorrência estão englobadas em cinco forças competitivas: a entrada de novos concorrentes, a ameaça de substitutos, o poder de negociação dos compradores, o poder de negociação de fornecedores e a rivalidade entre os concorrentes existentes. Essas cinco forças determinam a rentabilidade da indústria porque influenciam preços, custos e o investimento necessário (Porter, 2002b).

Porter (2002b) introduz, também, os conceitos de estratégias genéricas, baseado na premissa de que há maneiras distintas de se obter a vantagem competitiva dentro de determinada indústria. As principais estratégias apresentadas pelo autor são a de baixos custos e a de diferenciação, que implicam em qualificações e exigências diferentes, além de refletirem em diferenças na cultura e na estrutura organizacionais (Porter, 2002b).

As visões de estratégia apresentadas (Chandler, Andrews, Sloan, Ansoff e Porter) são classificadas por Mintzberg et al. (2000) como de prescrição, pois estudam como as estratégias necessitam ser formuladas, e não como realmente são criadas. Esses autores, portanto, buscam indicar as ferramentas e os procedimentos que apresentam os melhores resultados para a lucratividade das organizações. Para eles, a estratégia é uma decisão racional, sendo que o executivo principal formula estratégias com o objetivo de obter lucro em longo prazo (Mintzberg et al., 2000).

Whittington (2002), por sua vez, classifica esses pensadores como integrantes da abordagem clássica. Para tais pensadores, as estratégias são regras de longo prazo formuladas por meio de um processo racional de análises e cálculos deliberados, visando maximizar os lucros da empresa. Assim, os 
pressupostos principais dessa vertente são: análise racional, formulação e implementação como etapas diferentes e foco no lucro (Whittington, 2002).

Em contraposição a essa visão clássica, autores como Hannan e Freman (1988), Aldrich (2007) e Williamson (1991) apontam que o planejamento racional em longo prazo é, muitas vezes, pouco eficaz e desnecessário. Isso porque, nessa perspectiva denominada por Whittington (2002) de evolucionista, o ambiente é imprevisível. Além disso, é o ambiente que determina qual a melhor estratégia entre as adotadas pelas organizações, de forma que as estratégias bemsucedidas emergem quando ocorre o processo natural de seleção pelo ambiente. De tal forma, o ambiente define que empresas maximizarão seus lucros e, portanto, sobreviverão, restando às organizações buscarem se ajustar ao contexto em curto prazo (Whittington, 2002). Assim, as organizações ficam em situação de reatividade às mudanças do ambiente (Mintzberg et al., 2000).

No artigo, "The population ecology of organizations", publicado em 1977 e baseado na Teoria da Seleção Natural, de Charles Darwin, Hannan e Freemann focam os aspectos estruturais do ambiente, ou seja, nos fatores que determinam a sobrevivência de populações de organizações em um dado ambiente (Hannan \& Freemann, 1977).

Howard Aldrich publicou, em 1979, "Organizations and Environments", no qual apresenta uma visão evolucionista da relação entre organizações e seus ambientes, abordando variação, seleção, retenção e luta. $\mathrm{O}$ ambiente, para o autor, abrange recursos, poder, dominação política e outras organizações. É provável que a adaptação das organizações ao ambiente seja resultado do acaso, e não de uma estratégia deliberada (Aldrich, 2007).

Oliver Williamson escreveu "Strategizing, economizing and economic organization", em 1991, obra na qual defende que a produção de estratégias sustentáveis em longo prazo é uma visão perigosa e que a organização necessita trabalhar para reduzir em curto prazo seus custos de produção para atingir a eficiência relativa da própria empresa. Assim, o estrategista tem como função a redução dos custos, em especial os custos de transação, isto é, aqueles advindos da coordenação e organização do processo produtivo (Williamson, 1991).

A processualista é outra vertente da estratégia que se contrapõe à abordagem clássica, na qual se destacam autores como Cyert e March (1963), Pettigrew (1977), Mintzberg (2006a; 2006b) e Quinn (1989). A perspectiva do processo questiona o valor do planejamento racional em longo prazo, pois entende que os processos das organizações e dos mercados raras vezes são suficientemente perfeitos para o planejamento estratégico (Whittington, 2002).

Como destacam Cyert e March (1963), a racionalidade humana é limitada, pois a racionalidade plena exigiria do estrategista um conhecimento completo e anterior de tudo o que acontece no mercado. Para os autores, na realidade, esse conhecimento é fragmentado, fazendo com que o estrategista utilize de sua imaginação para cobrir as falhas da falta de informação, conhecimento e capacidade de cálculos. Whittington (2002) destaca que, ao rejeitar as ideias de homem racional econômico e da perfeição dos mercados competitivos, Richard Cyert, James March e Herbet Simon levaram em consideração a complexidade interna das organizações, embasando as ideias da abordagem processual.

Andrew Pettigrew publicou, em 1977, "Strategy formulation as a political process", em que defende que a formação da estratégia nas organizações é um processo contínuo e eminentemente político, relacionado à existência de pressões intraorganizacionais e ambientais. No que tange às pressões ambientais, destaca que a estratégia está vinculada a um fluxo de eventos, valores e ações relacionados a um contexto. Quanto a pressões intraorganizacionais, ressalta que as organizações são formadas por coalizões de indivíduos com interesses pessoais e inclinações cognitivas que barganham entre si para atingir objetivos comuns mais ou menos aceitáveis por todos (Pettigrew, 1977).

Em 1987, na obra "The strategy concept I: five Ps for strategy", Henry Mintzberg propõe a metáfora do artesanato para explicar a estratégia, a qual é vista como fruto de um processo adaptável e contínuo, no qual formulação e implementação não se separam. Isso porque os estrategistas trabalham em uma rotina exaustiva, caracterizada, principalmente, pela "brevidade, variedade e descontinuidade", estando, portanto, mais focados na ação do que no planejamento (Mintzberg, 2006b). Dessa maneira, para Mintzberg (2006a), as estratégias são emergentes, isto é, um padrão percebido a partir de um fluxo de ações ou decisões. Essas estratégias emergentes são fruto do aprendizado da organização com situações e ações nãoestratégicas (Mintzberg et al., 2000).

Em 1989, James Quinn publica "Strategic change: logical incrementalism”. Para Quinn (1989), as mudanças estratégicas nas organizações se caracterizam por uma sequência de passos de cunho altamente político que devem ser seguidos pelo líder das mudanças estratégicas. Assim, o autor ressalta a concepção de "Incrementalismo Lógico", reforçando o pensamento de que a estratégia é realizada por meio de pequenas mudanças, sem grandes saltos para o desconhecido (longo prazo).

Em oposição a essas críticas à teoria clássica de estratégia realizada pelos autores evolucionistas e processualistas, surge uma quarta abordagem, a sistêmica, que acredita na capacidade de as organizações planejarem suas estratégias e agirem de maneira efetiva em seus ambientes. Essa perspectiva considera que as estratégias de uma organização estão vinculadas ao contexto sociológico no qual se insere (Whittington, 2002). 
Em 1985, Mark Granovetter publica "Economic action and social structure: the problem of embeddedness", obra na qual apresenta uma teorização sociológica dos fenômenos econômicos a partir das relações sociais e como essas relações afetam as instituições (Granovetter, 1985).

Richard Whitley é outro autor que apresenta contribuições para a vertente sistêmica em estratégia. Entre as suas obras, destaca-se "Divergent Capitalisms", de 1999, que trata da diversidade dos resultados do capitalismo em diferentes regiões e entre empresas da mesma região a partir da análise das diferenças nos sistemas de negócios e sua relação com diferenças em contextos institucionais (Whitley, 1999). Assim, para essa perspectiva, as metas estratégicas e os modos de formulação dessas metas dependem da cultura, do contexto e das relações sociais de cada região ou país (Whitley, 1999).

De tal forma, o uso do planejamento formal e racional da estratégia pode ser importante para algumas organizações quando o ambiente no qual operam espera isso das mesmas, ou seja, quando essa forma de formulação de estratégias está legitimada no contexto (Whittington, 2002). Por outro lado, os estrategistas, algumas vezes, se desviam das estratégias formais que objetivam a maximização do lucro, porque fatores culturais, sociais e políticos criam interesses e objetivos organizacionais além do lucro. A busca desses objetivos, ainda que afastem a organização da maximização dos lucros, é entendida como perfeitamente racional, mesmo que a razão esteja, às vezes, oculta (Granovetter, 1985).

Whittington (2002) destaca que a mensagem principal da vertente sistêmica é "a estratégia deve ser sensível do ponto de vista sociológico". Isso implica em compreender que não há uma única meta buscada pelos estrategistas, assim como não há uma única forma de alcançar essa meta, pois, de acordo com o contexto, emergirão objetivos e processos diferentes. Assim, não é possível dizer que todas as empresas deveriam adotar determinado modelo ou visão, da mesma forma que é essencial que os estrategistas não supunham que todas as empresas (fornecedores, concorrentes, clientes e parceiros) pensem a estratégia da mesma forma (Whittington, 2002).

Outra vertente em estratégia que emprega uma visão sociológica é a de estratégia como prática social. Em 1996, o professor da Universidade de Oxford, no Reino Unido, Richard Whittington, em sua publicação "Strategy as practice", apresentou essa nova perspectiva como um novo campo de estudos para a área de estratégia (Whittington, 1996). Posteriormente, Paula Jarzabkowski, professora da Aston Business
School, também do Reino Unido, se destaca na área por apresentar um grande número de publicações e contribuições (Walter \& Augusto, 2009).

Nessa visão, a estratégia é conceituada como uma atividade situada e realizada socialmente, enquanto $\mathrm{o}$ ato de fazer estratégia (strategizing) compreende as ações, interações e negociações de múltiplos atores e as práticas que eles utilizam na realização dessa atividade (Jarzabkowski, Balogun \& Seidl, 2007). Portanto, considera-se a estratégia como social, ou seja, uma prática social relacionada com atuação e interação de diferentes estrategistas (Whittington, 1996). Whittington (2006) assinala que a visão sociológica encoraja a observação da estratégia em todas as manifestações e a aponta como algo profundamente enraizado na sociedade e nela conectado. Nessa linha, a estratégia abandona o caráter de algo pertencente à organização e torna-se um produto da atuação das pessoas dentro dessa organização (Whittington, 1996).

Santos, Sette e Tureta (2006) abordam que essa perspectiva, ao invés de focar no conteúdo ou no próprio processo da estratégia, procura entender a microvisão das atividades do cotidiano da organização. Esse modelo está ligado ao modo de fazer estratégia da organização (strategizing) e entender como os estrategistas agem e interagem (Whittington, 2003; Jarzabkowsky, 2005). Assim, existe, portanto, um interesse especial dessa abordagem pelo estrategista, por seu desempenho e pelo modo como atua na organização (Johnson, Melin \& Whittington, 2003).

Nessa concepção, todos são potenciais estrategistas, e a alta gerência é vista como participante na formulação estratégica ao invés de sua formuladora (Mantere \& Whittington, 2007). Os estrategistas moldam a atividade estratégica por meio de quem são, como agem e em quais práticas se baseiam ao agir (Jarzabkowski et al., 2007). Assim, o praticante pode não ser chamado formalmente de (ou ser percebido como) estrategista e não ter um cargo de destaque na organização, mas suas ações e interações podem contribuir para a estratégia da organização (Jarzabkowski, 2005).

\section{CONCEPÇÕES DE ESTRATÉGIA E DE ESTRATEGISTAS}

A partir da consulta a obras das vertentes de estratégia pesquisadas, elaborou-se um quadro-síntese das principais características de cada vertente para explorar as diferenças e semelhanças entre elas, como exibido no Quadro 1. 
Da Estratégia Clássica à Estratégia como Prática: Uma Análise das Concepções de Estratégia e de Estrategistas

\begin{tabular}{|c|c|c|c|c|c|}
\hline \multirow{2}{*}{$\begin{array}{l}\text { Concepção de } \\
\text { estratégia }\end{array}$} & \multicolumn{5}{|c|}{ VERTENTES DA ESTRATÉGIA } \\
\hline & Clássica & Evolucionária & Processual & Sistêmica & $\begin{array}{l}\text { Estratégia como } \\
\text { prática }\end{array}$ \\
\hline Surgimento & Anos de 1960 & Anos de 1970 & $\begin{array}{c}\text { Anos de } 1960 \text { e } \\
1970 \\
\end{array}$ & $\begin{array}{c}\text { Anos de } 1980 \text { e de } \\
1990 \\
\end{array}$ & $\begin{array}{c}\text { Meados dos anos de } \\
1990 \\
\end{array}$ \\
\hline $\begin{array}{l}\text { Principais } \\
\text { autores }\end{array}$ & $\begin{array}{l}\text { Chandler, Andrews, } \\
\text { Ansoff e Porter }\end{array}$ & $\begin{array}{l}\text { Hannan, Freeman, } \\
\text { Williamson e } \\
\text { Aldrich }\end{array}$ & $\begin{array}{c}\text { Mintzberg, } \\
\text { Quinn, } \\
\text { Pettigrew, } \\
\text { Cyert e March }\end{array}$ & $\begin{array}{l}\text { Whitley e } \\
\text { Granovetter }\end{array}$ & $\begin{array}{l}\text { Whittington e } \\
\text { Jarzabkowski }\end{array}$ \\
\hline $\begin{array}{l}\text { Principais } \\
\text { influências }\end{array}$ & $\begin{array}{l}\text { Economia e } \\
\text { militarismo }\end{array}$ & Economia e biologia & Psicologia & $\begin{array}{l}\text { Sociologia } \\
\text { econômica }\end{array}$ & Sociologia \\
\hline $\begin{array}{l}\text { Conceito de } \\
\text { estratégia }\end{array}$ & Racional & Fatalista & Pragmática & Relativista & Social \\
\hline $\begin{array}{l}\text { Finalidade da } \\
\text { estratégia }\end{array}$ & Lucro & Sobrevivência & $\begin{array}{c}\text { Satisfação dos } \\
\text { interesses } \\
\text { Diversos } \\
\end{array}$ & $\begin{array}{l}\text { Fatores culturais, } \\
\text { sociais e políticos. }\end{array}$ & $\begin{array}{c}\text { Não } \\
\text { consolidada }\end{array}$ \\
\hline $\begin{array}{l}\text { Descritiva/ } \\
\text { Prescritiva }\end{array}$ & Prescritiva & Prescritiva & Descritiva & Descritiva & Descritiva \\
\hline Protagonista & Executivo principal & Ambiente & Organização & $\begin{array}{c}\text { Contexto } \\
\text { sociológico }\end{array}$ & Estrategista \\
\hline $\begin{array}{l}\text { Processo } \\
\text { estratégico }\end{array}$ & $\begin{array}{c}\text { Planejamento } \\
\text { analítico e racional }\end{array}$ & $\begin{array}{l}\text { Adaptação ao } \\
\text { ambiente }\end{array}$ & $\begin{array}{l}\text { Processo } \\
\text { gradual, } \\
\text { contínuo e } \\
\text { adaptável }\end{array}$ & $\begin{array}{l}\text { Varia conforme o } \\
\text { contexto }\end{array}$ & $\begin{array}{l}\text { Elementos do } \\
\text { Strategizing }\end{array}$ \\
\hline $\begin{array}{c}\text { Formação de } \\
\text { estratégias }\end{array}$ & Deliberado & Emergente & Emergente & $\begin{array}{c}\text { Deliberado e } \\
\text { emergente }\end{array}$ & $\begin{array}{c}\text { Deliberado e } \\
\text { emergente }\end{array}$ \\
\hline $\begin{array}{c}\text { Formalização } \\
\text { das estratégias }\end{array}$ & Formal & Informal & Informal & Formal e informal & Formal e informal \\
\hline $\begin{array}{c}\text { Prazo para } \\
\text { implementaçã } \\
\text { o }\end{array}$ & Longo prazo & Curto prazo & Curto prazo & Longo e curto prazo & Longo e curto prazo \\
\hline $\begin{array}{c}\text { Nível de } \\
\text { Análise } \\
\end{array}$ & $\begin{array}{c}\text { Organizacional e } \\
\text { extraorganizacional }\end{array}$ & Extraorganizacional & Organizacional & Extraorganizacional & Microorganizacional \\
\hline
\end{tabular}

Quadro 1 - Características da concepção de estratégia para cada vertente Fonte: Adaptado de Whittington (2002).

Como destacado no Quadro 1, a abordagem clássica teve início nos anos de 1960, a partir de autores como Chandler (1962) e Ansoff (1965). Além desses, outros autores de destaque são Andrews (1971) e Porter (1991a; 2002b). A vertente evolucionária surgiu na década de 1970 com obras como as de Hannan e Freemann (1977) e Aldrich em 1979 (ver Aldrich (2007) na lista de referências). Outro importante autor dessa visão é Williamson (1991). Em relação à perspectiva processual, têm-se obras já na década de 1960, como Cyert e March (1963). Contudo, é a partir dos anos de 1970 que essa perspectiva ganha (assim como a evolucionária) espaço na área, em virtude dos previstos choques do petróleo, de 1974 e 1979, os quais levaram a fortes críticas à estratégia elaborada conforme os preceitos da abordagem clássica (Whittington, 2002). Como autores de destaque da abordagem processual após a década de 1970, têm-se Pettigrew (1977), Mintzberg (1987) (ver Mintzberg (2006a) nas referências) e Quinn (1989). O início da abordagem sistêmica data dos anos de 1980 e de 1990, com destaque para autores como Granovetter (1985) e Whitley (1999). Por fim, a abordagem de estratégia como prática surge em 1996, com Whittington (1996), sendo adotada por outros autores, entre os quais se destaca Jarzabkowski (2005).

No que tange às principais influências de cada abordagem, ressalta-se que a abordagem clássica está vinculada ao militarismo, do qual retira sua concepção de estratégia e de como realizá-la: plano sistemático e deliberado do estrategista (comandante ou executivo) a ser implementado pelos demais (exército ou gerentes) (Whittington, 2002; Vizeu \& Gonçalves, 2010). A esse respeito, Vizeu e Gonçalves (2010) destacam que 
Chandler teve contato direto com a cúpula militar dos Estados Unidos durante a Segunda Guerra Mundial. Tem-se, também, a influência da economia, que, segundo Rumelt, Schendel \& Teece (1991), fornece conceitos e técnicas para a área de estratégia, como a análise da estrutura da indústria de Porter. Para Whittington (2002), a noção de formulação da abordagem clássica é baseada na economia da Escócia do século XVIII.

As principais influências da vertente evolucionária são a economia e a biologia. O papel da economia, segundo Whittington (2002), está relacionado a pesquisas realizadas na área que indicavam contradição ao modelo de homem econômico-racional, como o de Hall e Hitch (1939), que notou que os gerentes não conseguiam maximizar os lucros e não sabiam empregar os mecanismos fornecidos pelos economistas. Assim, a resposta da economia a esse fenômeno foi atribuir ao mercado a responsabilidade pelas decisões. A biologia, por sua vez, teve influência a partir da teoria de evolução das espécies, de Darwin, de forma que as organizações mais adaptadas sobreviveriam no mercado, de forma similar ao que ocorre com as espécies durante a evolução (Whittington, 2002).

A perspectiva processual tem como principal área de influência a psicologia, principalmente a partir da American Carnegie School que indicou, entre outros aspectos, que a cognição humana encontra limitações em seus processos. Assim, se torna impossível ao homem ser completamente racional, como propunha a abordagem clássica (Cyert \& March, 1963). Outra influência da psicologia a partir da American Carnegie School foi a observação de que interesses individuais e inclinações cognitivas particulares existem em todas as organizações e que podem se sobrepor ao objetivo de maximização do lucro, uma vez que os integrantes necessitam barganhar seus diferentes objetivos para que todos fiquem relativamente satisfeitos (Whittington, 2002).

No caso da abordagem sistêmica, a sociologia econômica se destaca como principal influenciador. A obra de Granovetter (1985) é tida como fundamental para a nova sociologia econômica, ou seja, uma teorização sociológica dos fenômenos econômicos a partir das relações sociais (Marques, 2003). Rumelt et al. (1991) acrescentam que o conceito de custos de transação na empresa, de Williamson, é oriundo da área econômica.

A principal influência da estratégia como prática é a sociologia, pois deriva de um movimento da sociologia contemporânea denominada "volta da prática", o qual se embasa em teorias da ação, como as de Bourdieu, De Certeau, Foucault, Giddens e outros (Schatzki, Cetina \& Savigny, 2001). De acordo com Whittington (2002), essas teorias são diferentes, mas compartilham o reconhecimento das ligações da atividade cotidiana às propriedades estruturais da sociedade. Assim, Whittington (2007) destaca que a estratégia como prática apresenta um olhar mais sociológico sobre a estratégia, considerando que a estratégia consiste em algo que as pessoas realizam no âmbito social. Snow (1999) identifica diversas características dessa visão sociológica: sensibilidade a conexões e a relações; reconhecimento do enraizamento social; e alerta para problemas sociais.

Whittington (2002) trata de quatro conceitos básicos sobre estratégia, um para cada abordagem por ele destacada: racional (clássica), fatalista (evolucionista), pragmática (processual) e relativista (sistêmica). Acrescenta-se a essa uma quinta concepção de estratégia para a perspectiva de estratégia como prática: a social. Na vertente clássica, a estratégia é tratada como racional, como pode ser percebido nos apontamentos de Chandler, Andrews, Ansoff e Porter. De acordo com Chandler (1962), a estratégia é a definição dos objetivos organizacionais em longo prazo, bem como a delimitação de ações e recursos para atingi-los. Andrews (2001) define estratégia como decisões tomadas pela organização. Segundo Ansoff (1965), o executivo principal necessita trabalhar de maneira racional e formal. Para Porter (2002), as estratégias são compreendidas como formulações préexistentes (estratégias genéricas), como baixos custos e diferenciação, empregadas para obter vantagem competitiva perante a indústria.

Para a vertente evolucionista, é o mercado que determina a melhor estratégia, e não as organizações (Whittington, 2002), de forma que as organizações ficam em situação de reatividade às mudanças do ambiente (Mintzberg et al., 2000). Além disso, para Aldrich (2007), a adoção de estratégias de sucesso é provavelmente resultado do acaso. Assim, pode-se dizer que essa concepção de estratégia é fatalista.

A abordagem processual adota uma concepção de estratégia considerada pragmática, pois a estratégia emerge do aprendizado da organização (Mintzberg et al., 2000). Assim, a estratégia é formulada por meio de um processo adaptável, contínuo (MINTZBERG, 2006a) e político (Pettigrew, 1977). Ainda, para Quinn (1989), a estratégia é realizada por meio de pequenas mudanças incrementais.

A concepção de estratégia é, na abordagem sistêmica, relativista, uma vez que varia conforme a cultura, o contexto e as relações sociais (Whitley, 1999). De tal forma, não há uma única meta buscada pelos estrategistas, assim como não há uma única forma de alcançar essa meta, pois, de acordo com o contexto, emergirão objetivos e processos diferentes (Whittington, 2002). Granovetter (1985), por exemplo, aponta que as relações sociais afetam as instituições, assim como Whitley (1999) identificou diversidade dos resultados em diferentes regiões e entre empresas da mesma região em virtude das diferenças nos sistemas de negócios e sua relação com diferenças em contextos institucionais.

Segundo a estratégia como prática, a estratégia é social, ou seja, uma prática social relacionada com 
atuação e interação de diferentes estrategistas (Whittington, 1996). Jarzabkowski et al. (2007) acrescentam que a estratégia é uma atividade situada e realizada socialmente, que está conectada com atividades como planejamento estratégico, revisões, workshops de estratégia, conversas e discursos estratégicos. Apesar de, nas obras consultadas, o conceito de estratégia não ser definido de forma clara, nota-se que todos os apontamentos estão vinculados a ela como um fenômeno social.

Quanto à finalidade da estratégia, a maximização do lucro é apontada como principal objetivo da estratégia na visão clássica, como destacado por Sloan (1963) e Porter (2002b). Como destaca Whittington (2002), a lucratividade é, de acordo com a abordagem clássica, o objetivo primordial das organizações.

$\mathrm{Na}$ perspectiva evolucionária, por ter as forças ambientais externas comandando as mudanças e transformações do mercado, as ações estratégicas objetivam a sobrevivência organizacional diante das adversidades (Hannan \& Freemann, 1977). Whittington (2002) aponta que, para os evolucionários, o resultado buscado pelas organizações também é, assim como para os clássicos, a maximização dos lucros. Contudo, considerou-se que esse resultado é o meio pelo qual as empresas garantirão sua sobrevivência.

A visão processualista foi considerada por Whittington (2002) como vaga em sua justificativa para a estratégia. Todavia, por meio das leituras realizadas, considerou-se que, a partir dos pressupostos de complexidade interna das organizações, racionalidade limitada do ser humano e barganha política, a finalidade está em obter resultados diversos para satisfação relativa dos integrantes. A esse respeito, Pettigrew (1977) destaca que as organizações são formadas por coalizões de indivíduos com interesses pessoais e inclinações cognitivas que barganham entre si para atingir objetivos comuns mais ou menos aceitáveis por todos. Cyert e March (1963) acrescentam que as organizações satisfazem seus integrantes no lugar de maximizar lucros.

A finalidade da estratégia, segundo a abordagem sistêmica, relaciona-se com objetivos diversos despertados pelo ambiente social. Como indica Granovetter (1985), fatores culturais, sociais e políticos criam interesses e objetivos organizacionais além do lucro. Whittington (2002) acrescenta que "Os teóricos sistêmicos insistem em que as razões por trás das estratégias são peculiares a determinados contextos sociológicos".

No caso da estratégia como prática, não se identificou, nas leituras realizadas, uma finalidade consolidada para a estratégia. Isso pode estar relacionado ao surgimento mais recente dessa abordagem que ainda está se construindo, bem como ao observado que a definição de estratégia ainda não está clara na abordagem. Como destacado por Whittington (2007), a introdução precoce da perspectiva prática foi ambígua em sua terminologia e sem definições precisas para muitos conceitos.

Para compreender as abordagens, buscou-se, também, identificar seus protagonistas. Na vertente clássica, a responsabilidade pelo planejamento racional e formal é do executivo principal da organização (Ansoff, 1965; Andrews, 1998). Segundo a perspectiva evolucionária, é o ambiente (ou o mercado) que toma as decisões e determina que empresas sobreviverão (Hannan \& Freemann, 1977). A visão processual considera a complexidade interna das organizações (Whittington, 2002), destacando que a estratégia é resultado de seu aprendizado coletivo (Mintzberg et al., 2000). Para a corrente sistêmica, a estratégia varia conforme o contexto sociológico (sistemas sociais, relações sociais, cultura etc.) (Granovetter, 1985; Whitley, 1999). Por fim, a estratégia como prática destaca a importância do estrategista ou praticante de estratégia, pois considera que a estratégia é fruto da atuação e interação entre diferentes estrategistas, independentemente do cargo que ocupar na organização (Johnson, Melin \& Whittington, 2003; Jarzabkowski, 2005; Jarzabkowski Et Al., 2007; Mantere \& Whittington, 2007).

As perspectivas clássica e evolucionária foram consideradas prescritivas, enquanto as demais se apresentam como descritivas. Como destacado, a estratégia clássica são classificadas por Mintzberg et al. (2000) como de prescrição, pois estudam como as estratégias necessitam ser formuladas, e não como realmente são criadas. A vertente evolucionária também foi considerada prescritiva, pois indica que apenas sobrevivem no mercado as empresas que minimizam seus custos, maximizam seus lucros e se adaptam ao ambiente (Hannan \& Freemann, 1977; Williamson, 1991; Aldrich, 2007). Ressalta-se, contudo, que a perspectiva evolucionária não descreve modelo nem ferramentas a serem empregados para a formulação da estratégia, como ocorre na clássica. De tal forma, o caráter prescritivo da vertente evolucionária é menos abrangente e caracteriza menos a abordagem do que a clássica.

Processual, sistêmica e estratégia como prática, portanto, foram consideradas abordagens descritivas. Nota-se que essas abordagens buscam aprofundar como as estratégias são, de fato, criadas e exploram aspectos específicos dessa formulação (Mintzberg et al., 2000). A processual, por exemplo, acredita que a estratégia emerge do trabalho da organização e que não há a formulação de estratégias prontas, pois essas são, via de regra, realizadas por meio de pequenas mudanças e emergem do aprendizado da organização (Quinn, 1989; Mintzberg et al., 2000). A vertente sistêmica procura identificar as diferenças existentes entre as organizações e qual a relação dessas características com o contexto sociológico (Granovetter, 1985; Whitley, 1999). A estratégia como prática, por sua vez, procura saber como os estrategistas agem e interagem para a formação de 
práticas estratégicas, ou seja, como se dá o strategizing (Whittington, 2003; Jarzabkowsky, 2005).

Em relação ao processo estratégico, verifica-se que, para a abordagem clássica, a formulação da estratégia ocorre por meio de um planejamento analítico e racional (Chandler, 1962; Ansoff, 1965; Andrews, 2001; Porter, 2002b). Segundo a perspectiva evolucionária, a única coisa que as organizações podem fazer é se adaptar ao ambiente, buscando reduzir custos e maximizar a lucratividade para sobreviver (Williamson, 1991; Whittington, 2002). A vertente processual destaca que o processo estratégico é gradual, contínuo e adaptável, no qual formulação e implementação são indissociáveis (Quinn, 1989; Mintzberg, 2006a). Na sistêmica, considera-se que o processo estratégico varia conforme o contexto sociológico (Whitley, 1999). Por fim, de acordo com a estratégia como prática, o processo estratégico ocorre por meio da atuação e da interação dos estrategistas em episódios de práxis (Whittington, 1996; Jarzabkowski, 2005; Jarzabkowski et al., 2007).

No tocante à formação de estratégias, as perspectivas teóricas foram organizadas em estratégias deliberadas e estratégias emergentes. Relacionada a essa classificação, há a formalização das estratégias, na qual as vertentes foram separadas em formal e informal, além do prazo de implementação: curto ou longo.

A abordagem clássica aponta a formação de estratégias de maneira deliberada e formal, visto que o executivo decide qual serão as estratégias adotadas pela organização e com qual objetivo, formalizando-as em um plano (Chandler, 1962; Ansoff, 1965; Andrews, 2001; Porter, 2002b). Apesar de Chandler (1962) ter inicialmente indicado que essas estratégias seriam implementadas na sequência de sua formulação, a proposta de estratégias de longo prazo, de Ansoff (1965), se tornou a mais empregada e difundida.

As vertentes evolucionárias e processuais, em contraposição, defendem a estratégia emergente, informal e de curto prazo. Os evolucionários defendem que a elaboração de estratégias deliberadas, formais de longo prazo, é pouco eficaz e desnecessário, pois a adaptação ao ambiente é resultado do acaso (Hannan \& Freman, 1988; Williamson, 1991; Aldrich, 2007). Assim, nessa visão, as estratégias bem-sucedidas emergem quando ocorre o processo natural de seleção pelo ambiente, restando às organizações buscarem se ajustar ao ambiente em curto prazo (Whittington, 2002). Já os processuais acreditam que é dessa forma que as estratégias surgem nas organizações, ou seja, a partir de um processo gradual e contínuo de aprendizado e percepção (Quinn, 1989; Mintzberg et al., 2000; MINTZBERG, 2006a). Além disso, questionam a importância da formalização das estratégias em longo prazo (planejamento estratégico), pois a racionalidade humana é limitada e os mercados imperfeitos (Cyert \& March, 1963).
Para a vertente sistêmica e para a estratégia como prática, as estratégias podem ser tanto deliberadas, formais e de longo prazo quanto emergentes, informais e de curto prazo. Segundo a primeira, isso dependerá do contexto no qual a organização está inserida, visto que o planejamento formal de longo prazo pode ser importante em contextos que esperam isso das empresas (Granovetter, 1985; Whittington, 2002).

De acordo com a segunda vertente - a estratégia como prática -, os estrategistas empregam diferentes ferramentas e mecanismos para a realização da estratégia, como formulações, reuniões, seminários de estratégia, discursos, conversas informais, emprego de ferramentas etc. (Whittington, 1996; 2006; Jarzabkowski et al., 2007). Jarzabkowski (2005) destaca que mesmo as práticas estratégicas formais e explícitas têm um papel importante nessa perspectiva, uma vez que atuam como mecanismos mediadores por meio dos quais os praticantes interagem para atingir os fins estratégicos. Cloutier, LeBaron e Whittington (2010) acrescentam que os estrategistas podem traduzir seus objetivos em um documento, como um plano estratégico. Por outro lado, as práticas estratégicas também podem ser implícitas e carregadas de expectativas dos estrategistas (relacionadas à trajetória social de cada um), além de serem permeadas por regras formais e informais do contexto (Whittington, 2006; 2007; Jarzabkowski, Lê \& Feldman, 2009). Assim, segundo Jarzabkowski (2003), a estratégia como prática não é uma perspectiva linear e unidirecional, em que o gerente pensa e depois age, pois também abarca o conhecimento em ação e o aprender fazendo. Além disso, como destacam Kaschewsky e Jarzabkowski (2005), os estrategistas, muitas vezes, são integrantes que não possuem responsabilidade e papéis formais na elaboração de estratégias da organização.

Por fim, ainda no tocante ao Quadro 1, abordase o nível de análise das vertentes. A teoria clássica, primeiramente com os trabalhos de Chandler (1962) e Sloan (1963), trabalha em um nível organizacional, no qual os interesses e as ações da organização é que alimentam a realização da estratégia. Andrews (1971), com a análise SWOT, já traz um olhar para o organizacional e o extraorganizacional (mercado), com vistas à identificação de oportunidades e ameaças desse para a realidade organizacional. A linha economicista clássica eleva a análise para o nível da indústria (extraorganizacional), propondo uma análise bem mais ampla, abarcando concorrentes, fornecedores, clientes, novos entrantes e substitutos em suas ponderações (Porter, 1991a).

A perspectiva evolucionária avalia a estratégia como fortemente influenciada pelo contexto extraorganizacional, isto é, todos os fatores macroeconômicos podem interferir na formulação da estratégia e em sua implementação (Hannan \& Freemann, 1977; Williamson, 1991; Aldrich, 2007). De 
forma similar, a visão sistêmica destaca a influência do contexto sociológico (realidade social, histórica, política e cultural) na estratégia. Esse contexto abrange, principalmente, o nível extraorganizacional, como relações sociais, sistemas de negócios e contextos institucionais (Granovetter, 1985; Whitley, 1999).

A vertente processualista, por sua vez, volta-se à análise da estratégia ao nível organizacional, uma vez que valoriza os processos políticos internos (Cyert \& March, 1963; Pettigrew, 1977) e o aprendizado organizacional (Mintzberg et al., 2000). A estratégia como prática procura entender as atividades estratégias em nível micro (Whittington, 2003), relacionando as microatividades com os âmbitos organizacional e extraorganizacional, ou seja, adotando uma visão multinível entre comportamento individual, práticas organizacionais, normas sociais e influências do contexto (Jarzabkowski, 2005).

Sobre a ação do estrategista, no Quadro 2, resumem-se as principais diferenciações do entendimento do que é e de como atua um estrategista.

\begin{tabular}{|c|c|c|c|c|c|}
\hline \multirow{2}{*}{$\begin{array}{l}\text { Concepção de } \\
\text { estrategista }\end{array}$} & \multicolumn{5}{|c|}{ VERTENTES DA ESTRATÉGIA } \\
\hline & Clássica & Evolucionária & Processual & Sistêmica & $\begin{array}{c}\text { Estratégia como } \\
\text { prática }\end{array}$ \\
\hline $\begin{array}{c}\text { Posição } \\
\text { hierárquica }\end{array}$ & Topo & Topo & Topo e médio & Topo & Todos os níveis \\
\hline Racionalidade & Plena & Limitada & Limitada & Plena & Limitada \\
\hline Função & $\begin{array}{l}\text { Planejamento e } \\
\text { decisão }\end{array}$ & Percepção e reação & $\begin{array}{l}\text { Adaptação e } \\
\text { negociação }\end{array}$ & $\begin{array}{l}\text { Varia conforme o } \\
\text { contexto }\end{array}$ & Participação \\
\hline Atuação & $\begin{array}{l}\text { Planejamento } \\
\text { racional de } \\
\text { estratégias ou } \\
\text { seleção das } \\
\text { estratégias }\end{array}$ & $\begin{array}{c}\text { Reação às } \\
\text { mudanças ocorridas } \\
\text { no ambiente e } \\
\text { redução dos custos }\end{array}$ & $\begin{array}{l}\text { Negociação em } \\
\text { barganhas } \\
\text { políticas e } \\
\text { adaptação de } \\
\text { estratégias }\end{array}$ & $\begin{array}{l}\text { Desenvolvimento } \\
\text { de estratégias de } \\
\text { acordo com o } \\
\text { aceito no contexto } \\
\text { sociológico }\end{array}$ & $\begin{array}{c}\text { Criação, adaptação e } \\
\text { difusão de práticas } \\
\text { estratégicas }\end{array}$ \\
\hline
\end{tabular}

Quadro 2 - Características da concepção de estrategista para cada vertente Fonte: Elaborado pelos autores.

Para a abordagem clássica, os estrategistas estão em nível de topo: executivo principal (Ansoff, 1965; Andrews, 1998) e integrantes do departamento de planejamento (Ansoff, 1965). Contudo, é o executivo principal que tem papel principal, pois, mesmo que não seja ele o formulador das estratégias (no caso de existir um departamento pra isso), é ele quem decidirá que estratégias serão implementadas (Ansoff, 1965). Como destaca Andrews (1998), o executivo principal é o sujeito essencial nos rumos estratégicos organizacionais. $\mathrm{O}$ autor destaca, também, que participam das reuniões de planejamento estratégico os diretores e o nível mais elevado das equipes gerenciais. Assim, esses estrategistas assumem a função de planejadores racionais das estratégias (possuem racionalidade plena), atuando na formulação ou definição de quais serão adotadas. A esse respeito, Ansoff (1965) aponta que o executivo principal trabalha de maneira racional e formal na elaboração e difusão das estratégias na organização. Para Porter (2002b), os estrategistas empregam análise e raciocínio para escolher a melhor estratégia competitiva. $\mathrm{Na}$ concepção de Chandler (1962), os estrategistas definem os objetivos organizacionais, assim como as ações e recursos necessários para atingi-los.

Whittington (2002) complementa que a abordagem clássica considera os estrategistas como profissionais formados na área de administração, que utilizam a racionalidade e tomam decisões impessoais. Esses executivos chegaram a esse nível hierárquico em virtude de seus méritos. Mais recentemente, segundo o autor, surgiu uma nova concepção de estrategista na vertente clássica, a do líder heróico, que se refere a um integrante da alta gerência com visões mais amplas do que os cálculos dos profissionais. Esses gerentes são descritos como "pessoas carismáticas e talentosas, inspiradores em suas visões, audazes em seu comando", sendo enfatizado, portanto, suas características pessoais (Whittington, 2002).

$\mathrm{Na}$ perspectiva evolucionária, os estrategistas continuam sendo de alto nível hierárquico, não havendo, contudo, confiança em sua racionalidade, pois as melhores estratégias costumam ser resultado do acaso, e não de um planejamento (Aldrich, 2007). Como, para essa vertente, é o mercado que toma as decisões e que escolhe as melhores estratégias, cabe aos estrategistas perceber e reagir às mudanças nele ocorridas (Whittington, 2002). Williamson (1991) destaca que os estrategistas podem buscar, também, a redução dos custos, principalmente os de transação, para tentarem sobreviver.

A visão processual acredita que a racionalidade humana é limitada (Cyert \& March, 1963), além de não estar convencida de que a estratégia é resultado da atuação da alta gerência (Mintzberg, 1978). Isso porque, para essa abordagem, a estratégia emerge de 
um processo contínuo e gradual, no qual o nível intermediário (médio) da hierarquia realiza adaptações (Mintzberg, 1978). Essa vertente também aponta o processo político da estratégia, no qual os estrategistas necessitam negociar múltiplos interesses para que todos acabem razoavelmente satisfeitos (Pettigrew, 1977).

Para a abordagem sistêmica, assim como na clássica, a estratégia é resultado do trabalho racional de estrategistas em nível de topo (Whittington, 2002). No entanto, de acordo com a vertente sistêmica, a racionalidade dos estrategistas pode envolver objetivos diferentes do que a maximização do lucro (Granovetter, 1985). Outra diferença entre essas perspectivas está na consideração de como os estrategistas se tornam executivos: se, para a visão clássica, são os méritos relacionados com características pessoais que garantem a ascensão hierárquica, para os sistêmicos, é a conformidade a condições sociais, históricas e culturais do contexto (Whittington, 2002).

De acordo com essa perspectiva, a estratégia depende da cultura, do contexto e das relações sociais. Todavia, atuar no mesmo contexto não torna as estratégias das empresas similares, pois há pluralidade de recursos e normas de conduta em cada contexto (Whitley, 1999). Nesse sentido, de acordo com Granovetter (1985), o comportamento das pessoas está inserido em uma rede de relações sociais, definindo quais os comportamentos adequados para seus membros. Nota-se, portanto, que, para a abordagem sistêmica, a função dos estrategistas variará conforme o que é considerado legítimo em cada contexto. Assim, os estrategistas desenvolvem estratégias de acordo com o aceito no contexto sociológico no qual estão inseridos.

A estratégia como prática considera que os estrategistas podem ocupar diferentes posições hierárquicas nas organizações e até mesmo serem externos a ela (Whittington, 1996, 2006). Dessa forma, o que indica que um praticante é estrategista não é sua posição, mas sua participação nos episódios de práxis por meio dos quais são desenvolvidas as estratégias da organização (Jarzabkowski, 2005). Dessa forma, o strategizing compreende as ações, interações e negociações de múltiplos atores e as práticas que eles utilizam na realização dessa atividade. Além disso, os estrategistas moldam a atividade estratégica por meio de quem são, como agem e em quais práticas baseiamse ao agir (Jarzabkowski et al., 2007). Whittington (2006) acrescenta que os estrategistas são fundamentais para a criação e difusão de práticas estratégicas. Nesse contexto, percebe-se que os estrategistas participam de diferentes etapas do processo de strategizing, criando, desenvolvendo, adaptando e difundindo as práticas estratégicas. Pode-se indicar que, para essa abordagem, o estrategista não apresenta plena racionalidade, pois como indica Jarzabkowski et al. (2007), as práticas estratégicas podem apresentar resultados estratégicos que não tenham sido planejados ou articulados com a estratégia da organização. Whittington (2011) acrescenta que a profissão estratégica lida com problemas característicos de incerteza.

\section{CONSIDERAÇÕES FINAIS, CONTRIBUIÇÕES E PESQUISAS FUTURAS}

Este estudo teve por objetivo analisar as concepções de estratégia e de estrategistas segundo diferentes vertentes teóricas. Identificou que a concepção de estratégia varia entre as abordagens em relação a aspectos como influências teóricas, conceito de estratégia, finalidade da estratégia, protagonistas, processo estratégico, formação das estratégias, prazo para implementação e níveis de análise. Já a concepção de estrategista se modifica em relação à posição hierárquica, ao nível de racionalidade, à função e à atuação.

As definições de estratégia são diferentes em cada perspectiva, cabendo ao pesquisador, ao iniciar seu estudo, esclarecer a vertente teórica que embasará seus estudos.

Além disso, os pressupostos de temporalidade, formalização e racionalidade poderão dar subsídios às análises e ao entendimento tanto da formulação quanto da implementação da estratégia, pois, em uma perspectiva evolucionária, há uma maior ênfase nas decisões limitadas de curto prazo, enquanto que, na clássica, a estratégia é constituída no longo prazo, com disponibilidade plena de racionalidade.

O nível de análise de cada corrente também é de suma importância, pois pode direcionar a abrangência da pesquisa, haja vista que uma pesquisa empírica, na perspectiva da estratégia como prática, não poderá se limitar à narrativa do gerente de alto escalão e necessitará explorar a contribuição de todos os envolvidos no processo de fazer estratégia. Em contrapartida, uma visão evolucionária, portanto, extraorganizacional, necessita explorar a realidade macroeconômica como diagnóstico para a formulação estratégica.

Além disso, o conhecimento do estrategista aponta para o auxílio da escolha metodológica/instrumentos de coleta, pois, se for uma abordagem sistêmica, por exemplo, necessitará incluir questões sobre o contexto social, cultural e político em que a organização está inserida.

Assim, como contribuição teórica e prática, esta pesquisa pode auxiliar professores, alunos, pesquisadores e gerentes a terem uma visão mais ampliada das abordagens de estratégia existentes e as implicações para a compreensão da estratégia e dos estrategistas.

Como limitação da pesquisa, neste trabalho de classificação teórica, parte-se necessariamente de princípios explicativos que servem como 'ligações ideacionais' (da ideia) que permitem criar um "padrão plausível e coerente do que apreendemos" (Chia, 
1994), sem qualquer intenção de totalidade. Contudo, acredita-se que a proposta consiste em uma forma de buscar coerência teórica e, consequentemente, metodológica, ao olhar o processo estratégico e o papel do estrategista. Para pesquisas futuras, sugere-se explorar complementarmente o estado da arte em estratégia, e verificar como estes trabalhos se posicionam em relação às categorias de análise das concepções de estratégia e estrategista. Além disso, sugere-se analisar como estes conceitos são utilizados no ensino de estratégia no Brasil e também o impacto dessa diversidade em estudos empíricos no campo organizacional.

\section{REFERÊNCIAS}

Aldrich, H. E. (2007). Organizations and environments. Palo Alto: Stanford University.

Ansoff, H. I. (1965). Corporate strategy. Harmondsworth: Penguin.

Andrews, K. R. (1998). A responsabilidade dos diretores pela estratégia corporativa. In: Montgomery, C., \& Porter, M. Estratégia: a busca da vantagem competitiva. 2. ed. Rio de Janeiro: Campus.

Barney, J. B., \& Hesterly, W. S. (2007). Administração estratégica e vantagem competitiva. São Paulo: Pearson.

Berger, P. L., \& Luckmann, T. (2010). Construção social da realidade. Petrópolis: Vozes.

Cabral, A. C. A. (2006). A evolução da estratégia: em busca de um enfoque realista. In: Encontro Nacional Da Associação Nacional De Pós Graduação Em Administração, 22, 1998, Foz do Iguaçu. Anais... Rio de Janeiro: ANPAD.

Chaffee, E. E. (1985). Three models of strategy. Academy of Management Review, 10(1), pp.89-98.

Chandler, A. D. (1962). Strategy and structure. Chapters in the history of the American Industrial Enterprise, Cambridge: MIT Press.

Chia, R. (1994). The concept of decision: A deconstructive analysis. Journal of Management Studies, 31(6), 781-806.

Clausewitz, C. V. (1976). On War. Princeton: Princeton University Press.

Cloutier, C., Le Baron, C., \& Whittington, R. (2010). A multimodal study of strategy communication and take up. Canada: HEC Montreal.
Cyert, R., \& March, J. (1963). A behavioral theory of the firm. London: Blackwell.

Evered, R. (1983). So what is strategy? Long Range Planning, 16(3), pp. 57-72.

Granovetter, M. (1977). Economic action and social structure: the problem of embeddedness. American Journal of Sociology, 91(3), pp. 481-510.

Hall, R. L., \& Hitch, C. J. (1939). Price theory and business behaviour. Oxford Economic Papers, (2), $12-45$.

Hannan, M. T., \& Freemann, J. (1977). The population ecology of organizations. American Journal of Sociology, 82, pp. 929-964.

Kaschewsky, M., \& Jarzabkowski, P. (2005). Reinvent the rules: a social practice framework for investigating strategic innovation in the peripheries. In: European Group For Organization Studies Conference, 21, 2005, Berlin. Proceedings... Berlin, Freie Universität Berlin.

Jarzabkowski, P. (2003 January). Strategic practices: an activity theory perspective on continuity and change. Journal of Management Studies, 40(1).

Jarzabkowski, P. (2005). Strategy as practice: an activity-based approach. London: Sage Publications.

Jarzabkowski, P., Balogun, J. \& Seidl, D. (2007). Strategizing: the challenges of a practice perspective. Human Relations, 60(1), pp. 5-27.

Jarzabkowski, P., Lê, J. K. \& Feldman, M. (2009). Organising to reorganize: doing end-to-end management in practice. Working Paper. Aston University, Birmingham (UK). .

Johnson, G., Melin, L. \& Whittington, R. (2003). Micro strategy and strategizing: towards an activity-based view. Journal of Management Studies, 40(1), pp. 3-22.

Mantere, S., \& Whittington, R. (2007). Becoming a strategist: senior manager trajectories. In: European Group For Organization Studies, 23., Vienna, Austria, Anais... Viena: EGOS.

Marques, R., (2003). Os trilhos da Nova Sociologia Económica. In: Marques, R.; Peixoto, J. (Org.). A Nova Sociologia Económica: uma Antologia. Oeiras: Celta Editora. pp. 1-67.

Miles, R. E., Snow, C. C., Meyer, A. D., \& Coleman, H. J. (1978). Organizational strategy, structure, and 
process. Academy of Management Review, 3 (3), pp. 546-562.

Mintzberg, H., Ahlstrand, B., \& Lampel, J. (2000). Safári de estratégia: um roteiro pela selva do planejamento estratégico. Porto Alegre: Bookman.

Mintzberg, H. (2006a). Os 5 Ps da estratégia. In: Mintzberg, H., Lampel, J., Quinn, J. B., \& Ghoshal, S. O processo da Estratégia, 4. ed. Porto Alegre: Bookmann.

Mintzberg, H. (2006b). O trabalho do gerente. In: Mintzberg, H., Lampel, J., Quinn, J. B., \& Ghoshal, S. O processo da Estratégia, 4. Ed. Porto Alegre: Bookmann.

Mintzberg, H. (1978). Patterns in strategy formation. Management Science, 24(9), pp. 934-948.

Oliver, R.W. (2001, nov.-dez.). What strategy, anyway? The Journal of Business Strategy, 22(6).

Pettigrew, A. M. (1977). Strategy formulation as a political process. International Studies of Management \& Organization, 7(2), pp. 78-87.

Porter, M. E. (1991a). Estratégia competitiva: técnicas para análise de indústria e da concorrência. Rio de Janeiro: Campus.

Porter, M. E. (2002b). Vantagem Competitiva: criando e sustentando um desempenho superior. Rio de Janeiro: Campus.

Quinn, J. B. (1989). Strategic change: logical incrementalism. Sloan Management Review, 30(4), pp. 16-45.

Quinn, J. B, \& Voyer, J. Incrementalismo lógico: administrando a formação de estratégia. In: Mintzberg, H., Lampel, J., Quinn, J. B., \& Ghoshal, S. O processo da Estratégia, 4. Ed. Porto Alegre: Bookmann, 2006.

Rumelt, R. P., Schendel, D., \& Teece, D. J. (1991). Strategic management and economics. Strategic Management Journal, 12, pp. 5-29.

Santos. L. L. S., Sette, R. S., Tureta, C. (2006). A estratégia como uma prática social: em busca do que seja "fazer estratégia". In: Encontro Nacional Da Associação Nacional De Pós Graduação Em
Administração, 30, 2006, Salvador. Anais... Rio de Janeiro: ANPAD.

Schatzki, T. R., Cetina, K. K., Savigny, E. V. (2001). The practice turn in contemporary theory. Londres: Routledge.

Sloan, A. P. (1963). My years with General Motors. Londres: Sedgewick and Jackson.

Snow, D. A. (1999). PSA presidential address: the value of sociology. Sociological Perspectives, 42(1), pp. 1-22.

Vizeu, F., \& Gonçalves, S. A. (2010). Pensamento estratégico: origens, princípios e perspectivas. São Paulo: Atlas.

Walter, S. A., \& Augusto, P. O. M. (2009). A institucionalização da estratégia como prática nos estudos organizacionais. In: Encontro Da Associação Nacional Dos Programas De PósGraduação Em Administração, 33., 2009, São Paulo. Anais... Rio de Janeiro: ANPAD.

Whittington, R. (1996). Strategy as Practice. Long Range Planning. 5 (2).

Whittington, R. (2002). What is strategy - and does it matter? London: Tomson Learning.

Whittington, R. (2003) The work of strategizing and organizing: for a practice perspective. Strategic Organization, 1 (1), pp.119-127.

Whittington, R. (2006). Completing the practice turn in strategy research. Organization Studies, 27(5), pp.613-634.

Whittington, R. (2007). Strategy practice and strategy process: family differences and the sociological eye. Organization Studies, 28(10), pp. 1.575-1.586.

Whittington, R. (2011). The practice turn in organization research: towards a disciplined transdisciplinarity. Accounting, Organizations and Society, 36 (3) pp. 183-186.

Williamson, O. E. (1991). Strategizing, economizing and economic organization. Strategic Management Journal, 12, pp. 75-94.

Whitley, R. D. (1999). Divergent Capitalism. Oxford: Oxford University Press. 